\title{
Hermenêutica da permanência: preservar, conservar e restaurar
}

\author{
J. C. Marçal \\ DOI 10.20399/P1982-999X.2016v1n2pp47-62
}

\begin{abstract}
Resumo
A proposta deste artigo é estruturar filosoficamente os conceitos de preservação, conservação e restauração a partir de uma hermenêutica fenomenológica e ontológica que permita construir as bases para uma Filosofia da Arquitetura. Trata-se de usar as conquistas da ontologia de Martin Heidegger para vislumbrar como estes conceitos podem ser articulados de modo analítico, profundo e coeso, alcançando, assim, a determinação necessária para se erigir as bases filosóficas de uma interpretação arquitetônica destes mesmos conceitos.
\end{abstract}

Palavras-chave: Hermenêutica; Preservar; Conservar; Restaurar.

\begin{abstract}
The purpose of this article is to establishes a philosophical comprehension on preservation, conservation and restoration concepts from a phenomenological and ontological hermeneutics that allows to build the foundation for a Philosophy of Architecture. It is using the achievements of Martin Heidegger's ontology to envision how these concepts can be articulated analytically, deeply and cohesive, reaching thus the necessary determination to build the philosophical basis of an architectural interpretation of these same concepts.
\end{abstract}

Key-words: Hermeneutics; Preserve; Conserve; Restore.

\section{Apresentação: fundamentos para uma Filosofia da Arquitetura.}

O objetivo deste artigo é fundamentar filosoficamente os conceitos de preservação, conservação e restauração. Tais conceitos, no âmbito da Arquitetura mais especificamente nas teorias de restauração - carecem de profundidade por trafegarem apenas sobre a esfera ôntica, ou seja, a esfera do entendimento objetivo das coisas. Filosoficamente pode-se adentrar a esfera ontológica - a esfera do ser - e dar a tais conceitos mais apuro, clareza, profundidade e rigor. A delimitação ontológica seguirá os passos da Ontologia Fundamental de Martin Heidegger e seus desdobramentos; entretanto, antes seremos obrigados a explicitar certos conceitos presentes na ontologia grega - especialmente em Platão - para atingirmos uma compreensão razoável das conquistas de Heidegger. Passaremos pela determinação do ser e do não-ser, do uno e do múltiplo (uma das perguntas essenciais de Platão era: por que as coisas nascem, por que se corrompem e por que são?); mundo, ação e patrimônio. Estes passos iniciais nos permitirão pensar a permanência e a impermanência, o espaço, o tempo e a mudança, pontos focais de relevância para nossa determinação de preservação, conservação e restauração. A dinâmica filosófica destes conceitos nos obriga a encetar uma jornada pela História da Filosofia para conquistarmos a profundidade aqui almejada.

\footnotetext{
* Doutor em Filosofia pela UFPE. Professor da Devry Brasil (Faculdade Boa Viagem). E-mail:
} introitu@hotmail.com 


\section{Gradação ontológica: ser e não-ser.}

No Livro VI da República, Platão estabelece uma gradação ontológica da realidade através da figura da linha quadripartida. No diálogo, Sócrates sugere a Glauco que tome uma linha e a divida em quatro partes iguais. Na primeira divisão inferior teríamos as imagens ou sombras das coisas. A segunda divisão - de baixo para cima comportaria os objetos sensíveis cujas imagens seriam dadas na divisão anterior. Esta primeira divisão em duas partes inferiores compõe aquilo que Platão denominou de realidade sensível. A realidade inteligível compreende as duas divisões superiores onde teríamos inicialmente os entes matemáticos ${ }^{1} \mathrm{e}$, por fim, as Ideias e a Ideia do Bem. ${ }^{2}$

Esta abordagem de Platão indica a compreensão de uma realidade suprassensível e transcendente. Entretanto, esta interpretação metafísica do real já havia surgido no seu diálogo Fédon. A questão de fundo do diálogo era: por que as coisas nascem, por que se corrompem e por que são? Platão principia por demonstrar que a concepção de Anaxágoras de que a Inteligência ${ }^{3}$ é a causa de tudo está correta, mas faltou-lhe uma fundamentação adequada que Platão encontra ao assumir que a Inteligência "dispõe todas as coisas da melhor maneira possível"4, ou seja, atrela esta ao Bem. O alvo aqui é definir a causa real ou verdadeira ( $\tau$ ò $\alpha \imath \tau \imath o v ~ \tau \omega$ ov $\tau$ ) das coisas. A célebre passagem do Fédon - que ficou conhecida como a "segunda navegação" - conduz ao suprassensível exatamente por considerar que se encontra a verdade das coisas no pensamento ${ }^{5}$.

Vislumbramos que aqui Platão refunda uma compreensão ternária, ou seja, verdade-ser-pensamento. Sabe-se que Platão foi discípulo do eleata Parmênides cujo fragmento mais conhecido diz que "o mesmo é pensar e ser" ( $\tau$ ò $\gamma \alpha \rho \alpha v \tau o ̀ ~ v o \varepsilon ı v ~ \varepsilon \sigma \tau \imath v \tau \varepsilon \kappa \alpha \iota \varepsilon \imath v \alpha l)^{6}$. Neste sentido, o físico (ou sensível) não dá conta para explicar a causa das coisas - é preciso ir além e encetar uma navegação mais profunda, metafísica. Todavia, o próprio Platão cala frente ao fato de determinar filosoficamente um Princípio ( $\alpha \rho \chi \eta)$ primeiro e supremo e determina a causa das coisas na instância das Ideias e do Demiurgo. A Ideia procura traduzir a noção grega de $1 \delta \varepsilon \alpha \mathrm{e}$ $\varepsilon 1 \delta o \varsigma$ - termos que indicam mais precisamente a forma, ou seja, o objeto específico do pensamento na sua forma mais pura, a saber, o ser verdadeiro. Quanto ao vocábulo $\varepsilon 1 \delta o \varsigma$ traduz a ideia da forma interior da coisa, sua essência. A essência imutável das coisas - o ser uno - seria alcançada através de um processo intelectivo muito especial

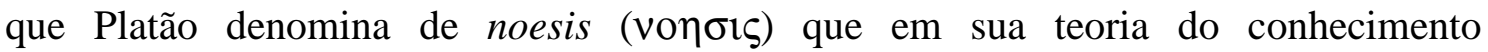

\footnotetext{
${ }^{1}$ Entenda-se que para Platão a matemática não é uma ciência em si mesma, mas sim um método, uma vez que a mesma funcionaria como um estágio intermediário entre a realidade sensível - estruturada em termos de unidade e multiplicidade - e a realidade inteligível superior, a ideia do Bem.

${ }^{2}$ Cf. PLATÃO. A República. Livro VI. São Paulo: Perspectiva, 2006.

${ }^{3}$ Inteligência ou pensamento possuía entre os gregos um sentido diverso daquele que poderíamos lhes atribuir hoje. O pensamento, entre os gregos, "denota, nos deuses, a nenhuma distância que vai do Nous à realidade plena: o que quer que um deus imagine, deseje ou intente acontece sempre - numa palavra, ée". (SANTOS, José Trindade. Antes de Sócrates. Lisboa: Gradiva, 1985, p. 107).

${ }^{4}$ REALE, Giovanni. História da Filosofia Antiga. São Paulo: Loyola, 1994, v. 6, p. 51.

${ }^{5}$ PLATÂO. Fédon, 99 d-100 a . Lisboa: EA, 1990.

${ }^{6}$ Foi Heidegger quem indicou que o enigma deste fragmento reside na compreensão da palavra $\tau$ ò $\alpha v 0 \tau$ ò - o mesmo. No seu curso O Princípio do Fundamento, temos a indicação de que tal mesmidade não se refere a uma identidade, mas sim de um manter-se junto no manter-se-afastado. Veremos mais à frente como Heidegger interpretará a identidade como base de toda Metafísica e como exigirá pensar o ser a partir da diferença. Na Analítica Existencial heideggeriana, a diferença ontológica responderá pela distância entre ser e ente - a esfera ontológica e a esfera ôntica.
} 
responderia pelo acesso às Ideias e ao Bem. Mas este ser uno platônico não é estanque como o ser de Parmênides.

Parmênides havia interditado o acesso ao não-ser. $\mathrm{O}$ eleata estabelece dois caminhos para o pensamento: um que é - a Realidade - e outro que não é - a Aparência; em outras palavras, o ser é o que tem de ser, enquanto o nada não é. Mas Platão não se sentia à vontade com esta interdição e sua ontologia busca uma dinâmica dialética do ser que torne possível à Filosofia pensar o não-ser. No diálogo O Sofista ocorre esta mudança, ou seja, o não-ser ganha estatuto ontológico. Uma das razões de Platão aqui era combater os sofistas que sustentavam a correspondência entre ser e aparência. Os sofistas, apoiados na doutrina de Parmênides, recusam a distinção entre ser e aparência, (porquanto seria esta inexistente) e de outra parte sustentam a correspondência entre ser e verdade, assim rejeitando haver o falso. $\mathrm{O}$ argumento afigura-se legítimo. "Dizer alguma coisa, mas não a verdade" parece impossível porque "dizer algo" significa "dizer o que é"; o pensar ou o falar se reportam necessariamente a algo que tem existência real, não podendo haver discurso sem um objeto real correspondente. Isto é possível porque não se poderia afirma nada sobre aquilo que não é. É neste momento que Platão conquista a definição do ser como potência ativa ou passiva para dar conta deste problema. $\mathrm{O}$ argumento platônico se inicia com a constatação da dupla realidade do movimento e do repouso em conexão com o ser. Movimento e repouso são inicialmente definidos como os mais opostos, embora ambos de fato sejam. Mas do ser não se diz que está em repouso ou que se mova, logo há três gêneros distintos entre si: ser, movimento e repouso. Mas o ser se mistura com o movimento e o repouso - sermovimento e ser-repouso falam do que é - enquanto os dois não se misturem com o ser. Mas o ser não pode se dissolver nesta relação triádica, sendo necessário que cada um seja o mesmo em relação a si próprio. Introduzem-se, então, mais dois gêneros: o mesmo e o outro. Porém, o movimento e o repouso participam do mesmo e do outro, apesar de não implicar que sejam o mesmo e o outro, pois o ser não é o mesmo e não é o outro. Porém, o outro indica a natureza da relação estabelecida entre os cinco gêneros aqui, ou seja, cada um dos gêneros é outro nomeadamente em relação ao ser ${ }^{7}$.

Tal alteridade nos diz que se o movimento é outro que o ser, então o não-ser é, uma vez que é outro que o movimento. Esta discussão visa atingir conclusões que são postas assim por José Trindade: 1. o discurso é a expressão verbal do pensamento (a dianoia); 2. consiste na afirmação e negação; 3. enquanto não verbalizado, é opinião; 4. esta pode ser verdadeira e falsa; 5. associado à sensação, constitui a aparência (phantasia) e 6. logo, a falsidade é possível ${ }^{8}$. Se o ser é e é outro em relação aos outros gêneros, pode-se concluir que estes são por participarem do ser, mas também se pode aduzir que não são, por serem diferente dele, constituindo coletivamente o não-ser. Assim, o não-ser é diferente do outro. O Estrangeiro - personagem principal deste diálogo - afirma que mostrar e parecer sem ser, falar entretanto sem nada dizer de verdadeiro é sempre uma questão de grandes dificuldades e ajunta que é preciso colocar a audaciosa suposição de que o não-ser existe, pois, de outro modo, o falso não poderia ser. O problema se inicia quando se afirma que o não-ser não pode ser atribuído a qualquer ser que seja e que ao ser se pode unir algum outro ser. A pergunta é: nunca seria possível unir algum ser ao não-ser? Quando falamos de não-ser não tentamos acrescentar-lhe a unidade? Mas não se diz que não é justo e correto querer ajustar o ser ao não-ser? A conclusão é: torna-se impossível pronunciar, dizer ou pensar o não-ser completamente só e que ele é, ao contrário, inconcebível, indizível, impronunciável e indefinível. Como enunciar algo sobre o não-ser se este não deve participar da unidade

${ }^{7}$ Cf. PLATÃO. O Sofista. São Paulo: DPL, 2005.

${ }^{8}$ SANTOS, José Trindade. "Existir" e "existência” em Platão. Revista Disputatio, n. 16, maio de 2004. 
nem da pluralidade, não podendo lhe atribuir a existência, a unidade ou a pluralidade numérica? Ora, da sequência lógica da ideia de que o ser envolve movimento e repouso - intercalando a noção do mesmo e do outro para justificar a individualidade do ser - e que o mesmo e o outro são chamados para redefinir o todo desta relação, concluí-se que o outro, pelo de fato de ser outro que o ser, só pode ser o não-ser, portanto o não-ser é.

\section{Da permanência e impermanência: o uno é; o múltiplo é.}

Este parricídio platônico aponta para o fato inegável de que a permanência é o ser e a impermanência é o não-ser. Entretanto, parece que o ser é uno em si mesmo, enquanto o não-ser - a dialética do real - opera no sentido da multiplicidade, do movimento, da mudança. Esta questão - do uno e do múltiplo - Platão discutirá no diálogo Parmênides. A tese fundamental do diálogo é: o uno é; o múltiplo é. Este diálogo traz três personagens: Sócrates, Parmênides e Zenão. O último - que também nasceu em Eleia e era discípulo e amigo de Parmênides - afirma que se os seres são múltiplos, "[...] então é preciso que eles sejam tanto semelhantes quanto dessemelhantes, mas que isso é impossível, pois nem as coisas dessemelhantes podem ser semelhantes nem as semelhantes, dessemelhantes"". Zenão afirma isto por querer dizer que o Todo, o ser, é uno. Sócrates pergunta, então, se Zenão não julga haver uma certa forma em si: daí haver um em si da semelhança e um em si da dessemelhança.Para Sócrates, não há problema em demonstrarmos que somos um e múltiplos. Ele afirma que a semelhança mesma é algo separada da semelhança sensível, da mesma forma que temos também o uno e as múltiplas coisas. ${ }^{10}$

O questionamento de Parmênides é o seguinte: se as formas são divisíveis, e as coisas que delas participam participariam de uma de suas partes, seria plausível admitir que a forma, uma, em verdade, se divide e mesmo assim permanece uma? Sócrates não admite esta tese que em si mesma parece ser contraditória. Aqui Parmênides inicia o célebre argumento do "terceiro homem". Eis o argumento:

Creio que tu crês que cada forma é uma pelo seguinte> quando algumas coisas, múltiplas, te parecem ser grandes, talvez te pareça, a ti, que as olhas todas, haver uma certa ideia uma e a mesma em todas; donde acreditas o grande ser um. / Dizes a verdade, disse ele./ Mas... e quanto ao grande mesmo e às outras coisas grandes? Se olhares da mesma maneira, com a alma, para todos esses, não aparecerá, de novo, um grande, um, em virtude do qual é necessário todas aquelas coisas aparecerem como grandes?/ Parece que sim. / Logo, uma outra forma da grandeza aparecerá, surgindo ao lado da grandeza mesma e das coisas que desta participam. E, sobre todas essas, <aparecerá> de novo uma outra, de modo a, em virtude dela, todas essas parecerem grandes. E não mais será uma cada uma das tuas formas, mas ilimitadas em quantidade ${ }^{11}$.

Sócrates responde que cada uma dessas formas é um pensamento e que não lhe cabe surgir em nenhum outro lugar a não ser nas almas. O problema é que o pensamento é sempre pensamento de algo, diz Parmênides. E retruca: “"Não é <pensamento> de

\footnotetext{
${ }^{9}$ PLATÃO. Parmênides. São Paulo: Loyola, 2003, 128 e.

${ }^{10}$ Ibidem, $130 \mathrm{~b}$.

${ }^{11}$ Ibidem, p. 131 e, 132.
} 
algo um, <algo> que esse pensamento pensa como estando sobre um todo, <algo esse> que é uma ideia uma?"12.

O argumento do terceiro homem significa que "não é possível algo ser semelhante à forma, nem a forma a outra coisa. Senão, ao lado da forma, sempre aparecerá outra forma"13. Tomemos o exemplo de Aristóteles: temos a ideia do Homem-Vivente-em-si e o Homem Vivente que anda, fala, sofre e ri. Para que este Homem de fato existisse, seria necessário que houvesse uma junção entre a ideia em si (Homem-Vivente-em-si) e o Homem-Vivente sensível. Assim, se há uma forma (uma ideia em si) de tudo o que é, seria necessário que houvesse uma ideia em si desta junção, aí teríamos uma nova ideia em si: a ideia em si do Homem-Vivente-em-si-e-doHomem-Vivente-sensível. E assim ad infinitum. Não teríamos uma base que nos possibilitasse, portanto, pensar o fundamento daquilo que é.

Para resolver esta aporia, o diálogo de Platão se desdobra em tese e antítese sobre as hipóteses que serão levantadas por Parmênides. De início, parece que "é-nos incognoscível tanto o belo mesmo, o que realmente é, como o bem e todas as coisas que concebemos como sendo ideias mesmas"14. Diante desta impossibilidade, Parmênides aceita fazer uma demonstração sobre o exercício de tirar consequências de hipóteses. A $1^{a}$ hipótese é: Se é um e tem como consequiência o fato de que ele não é nem todo nem partes. O um , sendo, não poderá ter fim nem limite e nem poderia ser coisas múltiplas. Não poderia ser o todo, já que este é composto de partes e nem poderia ser as partes mesmas. Não tendo fim e limite, não poderia ser nem reto e nem circular, já que redondo é aquilo cujas extremidades, em todos os pontos, distam igualmente do meio ${ }^{15}$ e reto aquilo cujo meio "esteja fazendo obstáculo às duas extremidades".

O um, então, também não estaria nem em si mesmo nem em outra coisa, logo não estaria no espaço e também não estaria nem em repouso e nem em movimento. Primeiro, é impossível algo estar em algo que não o envolva - e que uma coisa seria o envolvente e o outro o envolvido. Se assim fosse, o um seria agente e paciente, logo não seria um e sim dois. Da mesma forma, não poderia estar em movimento, já que o movimento se dá por alteração ou deslocação, o que não caberia ao um; por outro lado, não pode estar em repouso, pois como o um não pode estar nem em si mesmo e nem em outra coisa, o um jamais estaria no mesmo lugar ou estado. Tudo isto só é possível de pensar em relação aquilo que possui partes.

Do mesmo modo, o um nem é o mesmo e nem o diferente. "[...] se o um e o mesmo de maneira alguma diferem, toda vez que algo <se tornasse > um, <tornar-se-ia> o mesmo. - Perfeitamente. - Logo, se o um for o mesmo que si mesmo, não será um consigo mesmo, e, assim, sendo um, não será um"16.

Ora, o mesmo e o diferente nos indicam que o um também não seria o semelhante, nem tampouco o dessemelhante. Assim, também não seria nem igual e nem desigual, principalmente porque o um não é uma unidade de medida. A unidade matemática de medida parece ser derivada deste um primordial.

O um também não está no tempo. O tempo cronológico sempre nos diz de um anterior e um posterior, de um jovem e um velho e isto é sempre alteração. Quando algo está no tempo, é necessário que sua idade mude - e isto não caberia ao um.

Estas conquistas iniciais obrigam Parmênides a afirmar que sobre o um não há ciência, enunciação, percepção ou conhecimento. O que se falou até agora do um possui

\footnotetext{
12 PLATÃO, 2003, 132 c.

${ }^{13}$ Ibidem, 132 e.

${ }^{14}$ Ibidem, 134 c.

${ }^{15}$ Ibidem, 137 e.

${ }^{16}$ Ibidem, 139 d,e.
} 
caráter puramente negativo. Para operar de modo dialético, Platão deverá agora seguir o caminho positivo de sua argumentação. A $2^{\mathrm{a}}$ hipótese agora opera no sentido de tomar como base o um é e derivar suas consequiências de modo positivo. Primeiro teremos que ele, o um, é um todo e é infinitas partes. O argumento é interessante:

Se o é diz do um que é, e o um do que é um, e se a essência e o um não são o mesmo mas sim pertencem ao mesmo, àquilo que hipotetizamos, isto é, ao um que é, não será necessário que ele seja por um lado o todo um-que-é, e que, por outro lado, venham a ser partes dele tanto o um, quanto o ser? / É necessário. / Então, cada uma dessas duas partes deve ser chamada parte do todo? / Do todo. / Logo, aquilo que for um tanto é um todo quanto tem partes. / Perfeitamente. / E então? Será que cada uma dessas duas partes do um que é, o um e o ser, está privada <da outra: ou o um da parte ser, ou o ser da parte $u m$ ? / Não será possível. / Logo, uma vez mais, também cada uma das duas partes contém tanto o um quanto o ser, e a parte, por sua vez, vem a consistir de pelo menos duas partes; e, pelo mesmo argumento, é sempre assim: o que quer que precisamente seja parte, contém sempre essas duas partes [sc. O um e o ser]. Pois tanto o um sempre contém o ser, quanto o ser, o um. De modo que, tornando-se sempre dois, é necessário que jamais seja um. / Absolutamente sim. / Então, o um que é seria, assim, ilimitado em quantidade ${ }^{17}$.

O um e a essência, nesta instância, são diferentes em virtude do diferente e do outro $^{18}$. Mas quando digo essência e $u m$ digo, em verdade, ambos. Como o número se revela ilimitado e participante da essência, é natural que pensemos que se um é, "é necessário que também haja número" ${ }^{19}$. O ser e o um estão em todas as coisas, e aqui nos remetemos a Heraclito: Tudo é Um.

É nesta direção que a dialética, agora positiva, conquista a antítese: o um implica uma infinidade tanto de ser quanto de um (144); é reto e circular (144 d); está no espaço (145 b, c); está em movimento e repouso (145 e); é semelhante e dessemelhante (147 c); é contíguo e não contíguo (148 d); é igual e desigual (149 d, e); está no tempo (151 e), logo dele há ciência, opinião e percepção, pois “[...] o um era, e é, e será, e se tornava, e se torna, e se tornará [...] E ele pode ter algo e pode haver algo dele; tanto havia, quanto há, e haverá"20.

A $3^{\text {a }}$ hipótese platônica afirma que o um é e não é; ele muda. Como algo não pode participar e não participar ao mesmo tempo de outro, o um, na participação, participa ou não participa no tempo. Inicialmente, devemos entender que para Platão o instante significa o ponto a partir do qual a coisa muda, pois não é a partir do repouso que a coisa muda e nem a partir do movimento. É na natureza do instante - que se situa entre o movimento e o repouso e que está em tempo nenhum - que há mudança.Logo, partir do um para o múltiplo, quanto do múltiplo para o um teremos que este mesmo um não é as múltiplas coisas, "nem está se separando, nem se reunindo"21.

As outras hipóteses seguem direções diversas. A $4^{\text {a }}$ afirma que o um é e que as coisas são partes de um todo orgânico e recebem, ilimitadas em sua essência, um limite

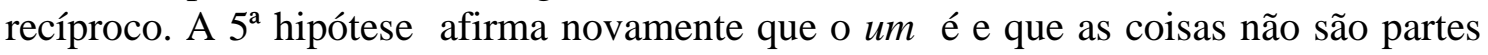
dele e não recebem nenhum atributo. A $6^{\text {a }}$ hipótese afirma que o um não é, mas é objeto

\footnotetext{
${ }^{17}$ PLATÃO, 2003, 142 d - e, 143.

${ }^{18}$ Para uma discussão sobre o ser e os gêneros dentro da dialética platônica (Cf. PLATÂO, 2005).

${ }^{19}$ PLATÃO, 2003, 144.

${ }^{20}$ Ibidem, $155 \mathrm{~d}$.

${ }^{21}$ Ibidem, 157 b.
} 
de pensamento. Questiona-se aqui se temos conhecimento do ser e do não-ser. Se dissermos que o um não é, devemos ter uma ciência deste não-ser, pois não poderia ser conhecido o conteúdo desta afirmação. Para haver conteúdo cognoscível nesta proposição, o um terá que possuir semelhança consigo mesmo e aí parece que relativizamos o não-ser, já que o não-ser absoluto não pode ser motivo de enunciação alguma. É assim que Platão poderá dizer que "[...] segundo parece, o um que não é é. Pois se ele não for algo que não é, mas se, de certa maneira, largar o ser por conta do seu não ser, imediatamente será algo que é" 22 .

A $7^{a}$ hipótese afirma que o um não é e que ele nem mesmo é objeto de pensamento. A $8^{\text {a }}$ hipótese afirma que o um não é e que as coisas têm pelo menos a essência de sua alteridade recíproca. Se o um não é, as outras coisas não são diferentes em relação ao um, mas sim em relação entre si. Deve-se determinar, portanto, onde se projeta a aparência de todas as determinações, já que é "[...] como quantidades que elas são outras em suas relações mútuas" ${ }^{23}$, pois não poderiam ser como unidades, já que, nesta hipótese, o um não é. O problema é que na multiplicidade delas, as coisas, deverá haver número, aparecendo cada uma como uma.

A $9^{a}$ e última hipótese afirma que o $u m$ não é e que as outras coisas não têm determinação, nem o ser nem aparência. As coisas não poderão nem ser o um nem o múltiplo, já que este "envolveria" o um como fundamento. Logo, se as coisas não são um, também não serão múltiplas, logo todas juntas "não são coisa nenhuma" ${ }^{24}$. Sem um, não poderíamos ter opinião sobre as coisas múltiplas. Neste longo percurso dialético encetado por Platão chega-se a uma conclusão plausível:

[...] se um não é, coisa nenhuma é. / Absolutamente sim. /Sendo assim, fique dito tanto isso quanto que, segundo parece, quer um seja, quer não seja, tanto ele mesmo quanto as outras coisas, tanto em relação a si mesmos quanto em relação uns aos outros, todos totalmente tanto são quanto não são, e tanto parecem quanto não parecem ser. / Absolutamente verdade ${ }^{25}$.

Torna-se, então, possível pensar o ser e o não-ser em conjunção com os sentidos de permanência e impermanência - sentidos fundamentais para a Filosofia da Arquitetura. A determinação de que o uno é e o múltiplo é permitem pensar tanto aquilo que se conserva em si mesmo como aquilo que deixa de ser, deteriorando-se. A partir desta abordagem inicial - em que se insere a História da Filosofia Antiga como base para as determinações ulteriores que serão conquistadas - perceberemos como as conquistas dos antigos pensadores gregos serão fundamentais para fornecer clareza e profundidade aos conceitos de preservação, conservação e restauração. Este passo permitirá alinhar a Filosofia com a Arquitetura numa nova dimensão conceitual.

\section{Desdobramentos da permanência: espaço filosófico e arquitetônico.}

Na Física de Aristóteles ( $\Delta$ 2, 209 a 31-b 2), o conceito de espaço está atrelado à noção de limite, uma vez que ali este é entendido como o comum no qual estão todos os corpos e é o lugar que imediatamente contém cada corpo. A concepção kantiana de espaço aponta para uma dimensão nova, já que retira da objetividade a primazia de

\footnotetext{
22 PLATÃO, 2003, 162.

${ }^{23}$ Ibidem, 164 c.

${ }^{24}$ Ibidem, 1665 e.

${ }^{25}$ Ibidem, $166 \mathrm{c}$.
} 
definí-lo. Para Kant, o espaço não se trata de um conceito empírico abstraído de experiências externas. Ao contrário, "o espaço é uma representação a priori necessária que subjaz a todas as intuições externas" ${ }^{26}$. Trata-se de uma intuição pura. O espaço é essencialmente uno, já que o múltiplo nele repousa apenas sobre limitações. A partir da exposição transcendental do conceito de espaço, Kant pode afirmar que ele "não é senão a forma de todos os fenômenos dos sentidos externos, isto é, a condição subjetiva da sensibilidade"27. E mais: "A forma constante dessa receptividade, denominada sensibilidade, é uma condição necessária de todas as relações em que objetos são intuídos como fora de nós" ${ }^{28}$. Há uma realidade empírica do espaço, mas há também sua idealidade transcendental, já que o mesmo não é nada "tão logo deixemos de lado a condição da possibilidade de toda a experiência e o admitamos como algo subjacente às coisas em si mesmas" 29 .

Merleau-Ponty segue as determinações de Kant e conclui que o sujeito da percepção e da ação é confrontado "com um mundo em que já existem direções absolutas" "30. A questão é: no interior da percepção, como é possível estabelecer estas direções absolutas, dado que "não podemos supô-las dadas na gênese de uma experiência espacial" "31? A resposta: o espaço está desde sempre já constituído, pois é de sua essência preceder-se a si mesmo, já que ser é sinônimo de ser situado. É notável que Heidegger - que foi neokantiano - estabelece a espacialidade a partir do Dasein (Die Räumlichkeit des Daseins) $)^{32}$, o "ser humano". O espaço não é algo dado fora externamente, nem tampouco é o Dasein um ente que atravessa o espaço como se ele mesmo fosse uma coisa corpórea. O Dasein, como diz Heidegger, não é um "devorador de quilômetros" ${ }^{33}$. A célebre afirmação de Heidegger ensina que:

O espaço nem está no sujeito nem o mundo está no espaço. Ao contrário, o espaço está no mundo na medida em que o ser-no-mundo constitutivo do Dasein já descobriu sempre um espaço. O espaço não se encontra no sujeito nem o sujeito considera o mundo 'como se' estivesse num espaço. É o 'sujeito', entendido ontologicamente, o Dasein, que é espacial em sentido originário. Porque o Dasein é nesse sentido espacial, o espaço se apresenta como a priori. Este termo não indica a pertinência prévia a um sujeito que de saída seria destituído de mundo e projetaria de si um espaço. Aprioridade significa aqui precedência do encontro do manual no mundo circundante ${ }^{34}$.

A dimensão ontológica e a dimensão ôntica do espaço permitem que Wittgenstein possa falar em variações do "ver espacial" "35. Tais variações se tornam

\footnotetext{
${ }^{26}$ KANT, Immanuel. Crítica da Razão Pura. São Paulo: Abril, 1983. p. 41.

${ }^{27}$ Ibidem, p. 42.

${ }^{28}$ Ibidem, p. 43.

${ }^{29}$ Ibidem, p. 43.

${ }^{30}$ MERLEAU-PONTY, M. Fenomenologia da Percepção. São Paulo: Martins Fontes, 1999, p. 339.

${ }^{31}$ Ibidem, p. 339.

${ }^{32}$ Cf. HEIDEGGER, Martin. Sein und Zeit. 19 ed. Tübigen: Verlag, 2006, p. 101.

33 Nesta constituição, a análise reserva os termos de dis-tanciamento e direcionamento para tratar da espacialidade do ser-em. Dis-tanciar é uma aproximação dentro da circunvisão e direcionamento é a tomada de direção dentro de toda aproximação. Ambos, dis-tanciar e direcionamento, determinam a espacialidade do Dasein de estar no espaço intramundano descoberto na circunvisão das ocupações, pois se trata de características constitutivas do ser-em.

${ }^{34}$ Ibidem, p. 111.

${ }^{35}$ Cf. WITTGENSTEIN, Ludwig. Investigações Filosóficas. 2. ed. Petrópolis: Vozes, 1996. p. 264.
} 
mais palpáveis quando nos debruçamos sobre a compreensão arquitetônica do espaço; tal compreensão, que opera no sentido de delimitar o espaço pelo seu viés ôntico, une os fundamentos de Kant e Heidegger - esfera ontológica - às concepções de MerleauPonty e Wittgenstein. Esta abordagem pode ter como referencial aquele dado por Evaldo Coutinho na sua obra $O$ Espaço da Arquitetura. Coutinho entende que a escultura - "mais que em qualquer outra arte" 36 - possui uma possibilidade de duração ímpar. Trata-se de um poder de sobrevivência - sobrevi-se à mudança, ao tempo, ao fluir da História. Neste sentido, "a parte construtiva, plástica, figurativa, da arquitetura, pertence à escultura" 37 . O espaço da arquitetura é realidade e não representação, segundo Coutinho. Este espaço é franqueado, "convertendo, a quem o penetra, em participante da própria essência espacial"38.

No espaço arquitetônico - dimensão prática da experiência espacial em seu sentido empírico e não transcendental - confluem diversas "entidades" que o determinam, são os epifenômenos do espaço: luz, sombra, ruído, silêncio, temperatura, etc. Este sentido empírico, contudo, fornece a dimensão plena das esferas do espaço a partir de sua transcendentalidade. Se o filósofo busca "converter todas as coisas a um sentido único" 39 , ou seja, voltar-se para a essência e fundamento daquilo que se manifesta, o artista (e aqui devemos ter em mente a comparação dada por Coutinho entre a escultura e a arquitetura) concentra-se na matéria: "a realidade lhe é então prescindível ante a fecundidade da matéria" ${ }^{40}$. Há a história do espaço - já que no espaço arquitetônico cada indivíduo que o perpassa torna-se participante de sua essência. Esta compreensão prática, que aponta inevitavelmente para a práxis espacial, aproxima Coutinho dos filósofos pragmáticos.

Como nos lembra Dewey, de Platão a Hegel "a Realidade Última é, ou perfeitamente Ideal e Racional na natureza, ou então tem idealidade e racionalidade como seus atributos" 41 . O problema que Dewey enxerga reside na transitoriedade, instantaneidade e fugacidade das coisas, dos fenômenos. Estas três determinações apontam para a própria história do espaço, do fenômeno espacial devido à participação daquele que adentra em sua essência. Para Dewey, "tempo, mudança, movimento são indícios de que aquilo que os gregos chamavam de 'Não Ser' de algum modo exprime a ideia do verdadeiro Ser" ${ }^{\prime 2}$. O espaço arquitetônico se dá exatamente nesta multiplicidade que advém do próprio tempo e do movimento, já que a mudança é aqui entendida como necessariamente "pluralidade numérica, multiplicidade" ${ }^{3}$. O espaço arquitetônico, assim como o Pragmatismo, não se cristaliza no Imutável. Há um modo novo de encarar as três determinações anteriores: "a mudança associa-se, agora, com o progresso, não mais com quedas e erros" 44 . Deve-se conhecer, estudar e dominar as mudanças para que estas colaborem na consecução de nossos desejos; eis a fonte do conhecimento prático. A Arquitetura, portanto, parece apontar para as duas frentes: ora para as determinações ontológicas dos entes - a esfera do Imutável - ora para as determinações ônticas - a esfera do Mutável. Na Arquitetura, o espaço ganha vida e suas expressões podem sofrer alterações através de determinadas ações humanas.

\footnotetext{
${ }^{36}$ COUTINHO, Evaldo. O Espaço da Arquitetura. 2. ed. São Paulo: Perspectiva, 1998, p. 1.

${ }^{37}$ Ibidem, p. 8.

${ }^{38}$ Ibidem, p. 38.

${ }^{39}$ Ibidem, p. 90.

${ }^{40}$ Ibidem, p. 97

${ }^{41}$ DEWEY, John. A Filosofia em Reconstrução. São Paulo: Nacional, 1958, p. 116.

42 Ibidem, p. 117.

${ }^{43}$ Ibidem, p. 118.

${ }^{44}$ Ibidem, p. 125.
} 


\section{Mundo, ação e patrimônio.}

Em relação à compreensão de Wittgenstein sobre mundo, escreve Apel: "O mundo é a quintessência dos 'fatos', os quais são retratados pelos fatos signicos da linguagem, ou então projetados no 'espaço lógico' como fatos [Tatsachen] ou como 'estados de coisas' [Saghverhalte]" 45 . Estas definições buscam demonstrar que um dos grandes problemas da Metafísica foi querer dar um sentido geral e global para mundo a forma do mundo e suas representações. Heidegger estava ciente dessas limitações e traça uma compreensão ontológica de mundo que passa por uma compreensão ôntica. $\mathrm{Na}$ analítica existencial heideggeriana é usada uma compreensão quaternária da questão do sentido de mundo: 1 . é conceito ôntico e significa a totalidade dos entes; 2. ontologicamente é o ser dos entes; 3. é o contexto, na esfera ôntica, "em que" de fato o Dasein vive e 4. trata-se do conceito existencial-ontológico da mundanidade - discussão do $\S 18$ e que traz à tona o conceito de conjuntura que se dá pela abertura da "significação como constituição existencial do Dasein, o ser-no-mundo" "que se trata de uma condição ôntica da possibilidade da descoberta da totalidade inerente à conjuntura.

$\mathrm{Na}$ determinação da mundanidade do mundo, Heidegger afirma que o manual vem ao encontro dentro do mundo. "O ser desse ente, a manualidade, remete ontologicamente, portanto, de alguma maneira, ao mundo e à mundanidade. Em todo manual, o mundo já está 'pre-sente'. Embora não de forma temática, o mundo já se descobre antecipadamente em todo encontro" "47. Dá-se homem, Dasein, e dá-se mundo: o mundo não é como um aquário em que pudéssemos colocar o homem. Em outro momento, Heidegger explicita esta ideia: 1. "“...]na formação de seu ser-aí (Dasein), o homem é formador de mundo" ${ }^{48} ; 2$." [...] mundo é a abertura do ente enquanto tal na totalidade"49 e 3. "[...] (o mundo) é o que permite a abertura dos múltiplos entes em seus contextos ontológicos diversos" $"$.

Esta determinação filosófica-ontológica nos permite vislumbrar dois pontos de extrema importância no que se refere às determinações da permanência na práxis humana em relação aos entes que se dão no mundo. Estes dois pontos são a compreensão de ação e patrimônio em que a prática humana se desdobra nas mais diversas construções de mundo. Como nos ensina Gregotti, "o reconhecimento do uso e da conexão é, portanto, indispensável para a percepção; nosso conhecimento se dá somente enquanto ação e participação, contínua transformação e construção de novos horizontes de utilização e de novos meios para" ${ }^{" 51}$. Não cabe aqui a discussão acerca da dimensão transformadora da teoria. Nosso intuito é desenvolver uma definição apurada para os conceitos de preservação, conservação e restauração; logo, para que esta empreitada chegue a termo, as determinações ontológicas servem como basefundamento ao todo estrutural de ações concretas - ações que mudam o mundo no modo como este se mostra onticamente. Há ação ${ }^{52}$ e participação que delineam

\footnotetext{
45 APEL, Karl-Otto. Transformação da Filosofia I. São Paulo: Loyola, 2000, p. 270.

${ }^{46}$ HEIDEGGER, 1988, p. 133.

${ }^{47}$ Ibidem, p. 127.

${ }^{48}$ HEIDEGGER, M. Os Conceitos Fundamentais da Metafísica. Rio de Janeiro: Forense, 2003, p. 404.

${ }^{49}$ Ibidem, P. 404.

${ }^{50}$ Ibidem, p. 405.

${ }^{51}$ GREGOTTI, Vittorio. Território da Arquitetura. São Paulo: Perspectiva, 1975, p. 113.

${ }^{52} \mathrm{Em}$ termos filosóficos, possuímos duas definições sobre a ação fundadas na tradição latina. A ação pode ser ação transeunte ou exterior (actio) significando a operação de um agente sobre outro ente e ação imanente ou interior (operatio) onde o agente se desdobra a si mesmo. No primeiro caso, podemos citar a ação de um escultor sobre o mármore e no segundo caso podemos citar o exemplo do crescimento de uma planta. Para a ontologia fundamental, a ação humana sobre as coisas é técnica - um meio com
} 
onticamente aquilo que se mostra. Entretanto, o que norteia estas ações não se dá no campo ôntico, mas sim ontológico, já que é a permanência quem estabelece historicamente a necessidade de se preservar, conservar e restaurar determinados entes que se dão no mundo. A totalidade dos campos em que estes entes se dão no mundo - a individualidade de cada campo em particular - denomina-se patrimônio. A arquitetura nos ajuda a contemplar com mais clareza estes campos ônticos e a delinear os planos necessários de ação que envolvem a permanência em cada um deles.

A ideia de patrimônio se associa a eixos explicativos: "o religioso, o monárquico, o familiar, o nacional, o administrativo e o científico"53. Respectivamente - e em termos sucintos - temos: 1. a sacralidade dos objetos religiosos como determinação de uma permanência; 2 . a ordem cultural do patrimônio monárquico dado pelas bibliotecas e arquivos reais que ensejam o desejo de proteção; 3. o patrimônio familiar e sua importância para determinada sociedade (como os castelos e as grandes coleções que permanecem no tempo); 4. o sentimento de unidade orgânica social dada pela ideia de patrimônio nacional que enseja a necessidade de "preservar e valorizar os bens representativos da nação" 54 e 5 . os estágios administrativos e científicos "como etapas nas quais, tendo a noção de patrimônio se consolidado, o Estado e a sociedade procuraram corrigir assimetrias e desequilíbrios na administração do patrimônio" 55 .

Salvar da perda e da degradação materiais que compõem tais estágios patrimoniais não apenas significa "eleger pontos de contato com o passado, de modo a permitir à sociedade contemporânea identificar-se e estabelecer uma continuidade imaginária com o conjunto patrimonial" ${ }^{156}$, mas também expressar sempre uma noção inconsciente de permanência. Como nos diz Heidegger, "apenas aquilo que é trazido à permanência num representar fundamentado pode valer como ente" ${ }^{\text {. }}$. Mas é o ser entendido aqui à luz da ontologia fundamental - que assinala o permanecer-ausente ( das Wegbleiben) em toda a extensão de sua história. O ser se mostra em sua clareira, mas esta também o esconde uma vez que o ser se re-vela, ou seja, se mostra e se oculta - a fonte originária de todo movimento. Tal mostrar-se e ocultar-se permitem não apenas que qualquer discurso seja verdadeiro ou falso ( Veritas $-\alpha 9 \lambda \eta / \theta \varepsilon 1 \alpha$ em seu sentido ontológico radical), mas também que a permanência seja e que a mudança possa existir.

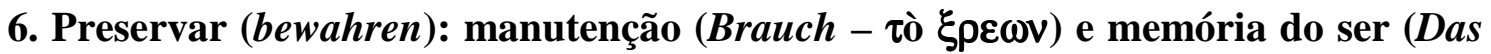 Gedächtnis des Seins).}

A experiência grega do ente como presente já surge quando Homero caracteriza o Vidente como aquele que viu, que conhecia. Como ele sempre já viu é que o mesmo possui o poder de ver e pre-ver. Zarader nos pergunta: o que é que o Vidente antecipadamente viu? Ela responde: "Homero nomeia-o triplamente: o ente ( $\tau \alpha \tau \varepsilon \circ \nu \tau \alpha)$, o ente-a-vir ( $\tau \alpha \tau \varepsilon \sigma \sigma o \mu \varepsilon v \alpha)$, o ente-que-foi $(\pi \rho \sigma \tau \varepsilon \sigma \nu \tau \alpha)$ "58.O ente $(\tau \alpha \tau \varepsilon o v \tau \alpha)$ é o que é em oposição ao que foi e ao que será. - diz o ente no sentido do

vistas a um fim (sentido derivado que advém da causalidade). A técnica é uma forma de produção (Hervorbringen) que opera, no sentido da técnica moderna, como provocação e não mais produção no

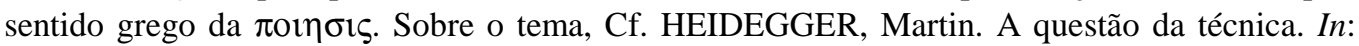

Ensaios e Conferências. 2. ed. Petróplis: Vozes, 2002.

${ }^{53}$ BO, J. B. L. Proteção do Patrimônio na UNESCO. Brasília: UNESCO, 2003, p. 22.

${ }^{54}$ Ibidem, p. 24.

55 Ibidem, p. 25.

${ }^{56}$ Ibidem, p. 27.

${ }^{57}$ HEIDEGGER, M. O Princípio do fundamento. Lisboa: Piaget, 1999, p. 48.

${ }^{58}$ ZARADER, Marlene. Heidegger e as palavras de origem. Lisboa: Piaget, 1998, p. 115. 
presente. Entretanto, é também dentro desta esfera de passado e futuro que o ente pode ser pensado. O ponto fundamental aqui é: "[..] é possível ao ente a demora no desvelado (logo, estar 'presente') que o seu ser-velado é ainda uma maneira de se relacionar com essa região e, através disso, se desdobrar como presente (anwesend)" ${ }^{\prime 59}$. O Vidente, então, é aquele que vê os três entes: presente-passado-futuro. Aqui se formula a concepção de que estar no presente, em seu sentido mais radical, é compreender o ente como presentemente desvelado, mas sem perder sua instância de ausência.

O que se vê aqui é uma memória. O Vidente é aquele que "vê mais longe do que o que se demora no desvelado" 60 . Ele conservar a "memória do ser" ( Das Gedächtnis des Seins). Heidegger entendia esta presença do presente através de uma palavra de Anaximandro - $\xi \rho \varepsilon \omega v$. Entendamos: o presente indica a experiência grega do ente, enquanto presença nomeia o ser. Já nas páginas iniciais de Ser e Tempo Heidegger diz: "o ser é sempre o ser de um ente"61. O filósofo alemão traduz $\tau$ ò $\xi \rho \varepsilon \omega v$ por der Brauch, manutenção e que indica algo como uma primeira figura do ser - "figura imperceptivelmente marcada por um vestígio da diferença" ${ }^{62}$. Assim, o ser se mostra e se oculta no tempo-história como presente, passado e futuro, tendo como primeira figura de seu des-velar a manutenção, o permanecer aberto de sua clareira que pode, também, ocultá-lo, mas que se perpetua pela memória.

O sentido dado ao verbo preservar (bewahren) pela ontologia fundamental está diretamente ligado à compreensão do homem como pastor do ser. Na sua Carta Sobre o "Humanismo" de 1949, Heidegger define que a essência do homem reside em sua ecsistência, ou seja, "o morar ec-stático na proximidade do ser" ${ }^{63}$. O homem, o Dasein, é o único ente que sendo está sempre em jogo o seu próprio ser - tendo sua essência nomeada como ser-no-mundo: "o homem é e é homem enquanto é o ec-sistente. Ele está postado, num processo de ultrapassagem, na abertura do ser, que é o modo como o próprio ser é" 64 . A ec-sistência significa estar exposto na verdade do ser: "o estar posto na clareira do ser denomino eu a ec-sistência do homem"65 - e a clareira mesma é o ser. $\mathrm{O}$ homem protege a verdade do ser e isto, ontologicamente, determina o homem para além do animal rationale. O homem, nos diz Heidegger, não é o senhor do ente, mas sim o pastor do ser ${ }^{66}$. O homem salvaguarda, mantém, preserva esta verdade que possui como morada a linguagem.

A diferença ontológica - ser e ente - permite divisar com mais clareza e profundidade o sentido do vocábulo preservar. Em seu sentido mais pobre, preservar indica manter livre da corrupção. Corrupção, na tradição latina corruptionis, significa alteração, deterioração ou depravação. A corrupção só pode se estender àquilo que é passível de se estragar, de se corromper e mudar e quem muda é o ente. Mas o sentido de preservar atrelado à alteração permanece obscuro, uma vez que um ente pode manter seu ser exatamente pela mudança entendida aqui como o velar e desvelar de seu ser. A memória do ser é dada pela sua história enquanto mudança. Esta confusão pode nos levar a entender a preservação no sentido estritamente ôntico, assim como o faz Salvador Viñas que a define como a "atividade que consiste em adequar as condições

\footnotetext{
59 ZARADER, 1998, p. 117.

${ }^{60}$ Ibidem, p. 117.

${ }^{61}$ HEIDEGGER, 1988, p. 35. No original: "Seins ist jeweils das Sein eines Seienden”. O importante aqui é perceber a similitude ortográfica entre ser e ente em alemão.

${ }^{62}$ ZARADER, 1998, p. 129.

${ }^{63}$ HEIDEGGER, M. Carta Sobre o "Humanismo". In: ed. São Paulo: Abril, 1984. (Os Pensadores). p. 164.

${ }^{64}$ Ibidem, p. 168.

${ }^{65}$ Ibidem, p. 154.

${ }^{66}$ Cf. Ibidem, p. 163. 
ambientais em que se haja um bem para que este se mantenha em seu estado presente" ${ }^{67}$. Mas em que consiste este estado presente? Como delimitar o que venha a ser este presente aqui entendido: identidade, imobilidade, memória? No caso da preservação de uma floresta, por exemplo, o seu presente é dado sempre pela mudança não podemos preservá-la para que a mesma se mantenha estática numa dimensão temporal dada, o presente. A figura do Vidente acima citada nos leva a perceber que a presença do presente, o ser, se mostra e se oculta e neste caso aqui - uma floresta - a memória do ser não se dá do mesmo modo como poderíamos pensar numa escultura de mármore de Praxíteles, por exemplo. No caso da floresta, preservar indicaria melhor um modo de evitar que qualquer ação humana pudesse interferir em seu processo de ser - entendido aqui como ser naturalmente vigente, o meio-ambiente. Não se trataria de ações sobre o ente específico, mas sim ações que visam evitar quaisquer ações sobre o mesmo, ou seja, uma ação com fins de não-ação.

É neste sentido que ontologicamente podemos entender preservar como unida à compreensão ontológica de manutenção. Manter o ser vigente ou recuperar a memória do ente que foi para que no futuro esta memória possa ser presente na presença mesma do presente, o ente. Preservar, portanto, deve ser definido em dois âmbitos: ôntico e ontológico, ou seja, na esfera dos entes e na esfera do ser. Assim, temos: 1. Preservar, ontologicamente entendido, é a vigência no aberto do ser em sua unidade-memória, a manutenção temporal de sua memória de ser; 2. Preservar, em sentido ôntico, nos fala de ações positivas ou negativas no seio do próprio ente ou em direção a este para que a presença do presente se mantenha na vigência do tempo histórico; 3. Preservar, em ambos o sentidos, indica uma atitude (a vigência) ou uma ação (relação) determinada para que um ente dado possa manter-se no aberto de sua vigência, seu ser.

\section{Conservar (aufbewahren): declínio (Untergehen) e reunir (zusammenbringen)}

No âmbito estritamente ôntico, podemos seguir Viñas e admitir que a conservação significa "a atividade que consiste em preparar um bem determinado para que experimente a menor quantidade possível de alterações intervindo diretamente sobre ele, inclusive alterando ou melhorando suas características perceptíveis" ${ }^{68}$. Contudo, na esfera ontológica esta definição se esfumaça no ar devido à sua precariedade. Já vimos que a presença do presente e a memória do ser "funcionam" como bases estruturais para que aquilo que se mostre possa ser apreendido e, deste modo, ser conteúdo para uma ciência. Mas o que se mostra é sempre o ser. A palavra

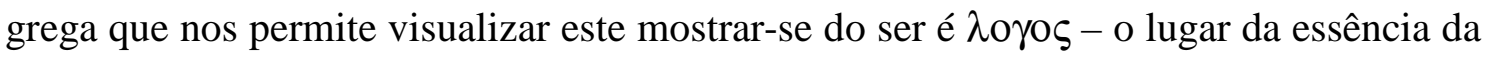
verdade entendida aqui em seu sentido ontológico mais radical. A palavra $\lambda$ o $\gamma \circ \varsigma$ deriva do verbo $\lambda \varepsilon \gamma \varepsilon ı v$ - dizer e falar. Em alemão temos a palavra legen que diz o mesmo que $\lambda \varepsilon \gamma \varepsilon ı v$ : "de-por, no sentido de estender e prostrar, pro-por, no sentido de adiantar e presentar" $"$. Heidegger aproxima o sentido de legen a lesen que é uma variação de ajuntar, por em conjunto, daí seu sentido mais comum, ler. A colheita possui proximidade com legen e lesen: Traubenlese. Juntar delimita a área em comum entre apanhar e colher. Há no recolhimento, portanto, uma vigência que opera uma ação de conservar. Explica Heidegger:

\footnotetext{
${ }^{67}$ VIÑAS, Salvador Muñoz. Teoría Contemporánea de la Restauración. Madrid: Síntesis, 2003, p. 23.

${ }^{68}$ Ibidem, p. 23.

${ }^{69}$ HEIDEGGER, M. Logos (Heraclito, fragmento 50). In: 2002, p. 184.
} 
Aquele 'mais' do colher ultrapassa o mero ajuntamento, por não lhe vir acrescentar-se de fora e, muito menos ainda, por lhe ser o último ato, servindo-lhe de conclusão. O conservar da colheita toma para si e assume o início de todos os passos de colher no encadeamento de sua sequiência. Olhando-se apenas a sucessão dos atos, vemos somente uma série em que ao apanhar e colher se segue o ajuntar, a este, o recolher, a este, o albergar em silos e no celeiro [...] Abrigar é o primordial na essência estruturante da colheita.

Há uma intenção aqui oculta: em toda colheita se mantém a ideia de preservar no tempo, até o consumo, certo ente. Abriga-se aquilo que se quer preservar de uma mudança que deteriore o ente em seu traço originário fundamental, ou seja, aquilo que o define a partir de seu ser e não de seu não-ser ${ }^{70}$. Tal processo possui raízes mais profundas fincadas na emergência do mostra-se do ser. Os gregos possuíam uma palavra para aquilo que eclode, declina e se oculta: $\phi v \sigma ı \varsigma$. A tradução mais comum de $\phi v \sigma ı \varsigma$ é dada como Natureza. Mas Heidegger desmembra este sentido em três palavras alemãs essenciais: Aufgeben, Untergeben e Verbergung - eclosão, declínio e ocultação. Como Aufgeben a Natureza é "o desabrochar, diz o nunca-soçobrar e define-se assim pela sua oposição à ocultação" "71. Contudo, a $\phi v \sigma ı \zeta$ também se inclina à ocultação, já que a Aufgeben é em si mesma uma ocultação que manifesta sua essência como esconder-se ( Sichverbergen) que se porta como um abrigar (Bergen). A $\phi v \sigma ı \varsigma$, neste sentido, é um "perpétuo desabrochar para fora do desvanecimento"72, é um jogo de eclosão e ocultação. O ser é definido, portanto, como $\phi v \sigma ı \varsigma$ e isto parece apontar para uma duplicidade de sentido. Entretanto, Heidegger se vale desta dinâmica do ser para compreender seu sentido como aquele que se destina em duas frentes: 1. é diferente do ente (sendo este puro desvelamento) sendo entendido aqui como o laço entre velamento e desvelamento e 2. é nomeado na medida em que inclui em si a diferença do ente.

Assim, parece plausível colocar na colheita o reunir (zusammenbrigen) no seio da mudança sem alterar a definição ontológica do ser. Reúne-se aquilo que, pelo declínio, pode se ocultar. O padecer, o perecer, o deixar de ser não opera aqui no sentido de uma destruição do ser - já que isto é próprio do ente - mas sim no sentido do seu velamento, de sua ocultação. Conservar (aufhewahren), portanto, também opera nos dois âmbitos anteriormente dados na conceituação de preservar. Deve-se entender a conservação em seu sentido ôntico e em seu sentido ontológico. Assim temos: 1. Conservar, em seu sentido ontológico, é a vigência da eclosão (Aufgeben) própria do ser em seu ente na sua abertura; 2. Também indica a demora histórica-temporal desta vigência no ente; 3. Conservar, em termos ônticos, aponta para ações exteriores que visam manter a memória do ser no sentido de sua eclosão originária; 4. Por fim, conservar indica a própria ação interior do ente em se manter vigente na abertura de sua eclosão. Em todos os sentidos, conservar é uma busca pelo manter distante o declínio (Untergeben) e a ocultação (Verbergung).

\section{Restaurar (restaurare): salvar (retten) e o idêntico (}

A tradição latina define restaurar (restaurare) como restabelecer, reconstruir, trazer o mesmo à luz da diferença. O idêntico, o mesmo surge como norteador para

\footnotetext{
${ }^{70}$ Pensemos nas sementes adequadas ao consumo como o ser e as sementes estragadas como a negação deste ser; entretanto, esta negação possui também em si mesma um ser que se mostra como um não à vigência anterior.

${ }^{71}$ ZARADER, 1998, p. 51.

72 Ibidem, p. 55.
} 
sabermos o que se quer conquistar com a restauração. $\mathrm{O}$ fragmento 3 de Parmênides é a primeira indicação do pensamento da identidade. O fragmento nos diz que "[...] o mesmo é para pensar (noein) e para ser (einai)"73. O que impõe pensar aqui não é o pensar e o ser, mas sim o caráter de mesmo - $\tau$ ò $\alpha v \tau$. Ser e pensar - que fundam o centro gravitacional do fragmento - não apontam para uma unidade ou igualdade absoluta, são coisas diferentes. Neste sentido, o mesmo indica uma relação de pertença mútua de dois termos. A mesmidade passa a ser entendida como o manter-se junto no manter-se afastado. No caso do fragmento de Parmênides, o pensamento está a caminho do ser, mas deve ser pensado como já no interior do ser.

$\mathrm{Na}$ compreensão dada anteriormente sobre a $\phi v \sigma ı \varsigma$ grega, os três momentos distintos da mesma indicam, contudo - apesar da diferença - o mesmo. O ser não é pensado mais a partir da identidade, mas sim da diferença, ou seja, a diferença entre ser e ente. Entretanto, é o na presença do Aufgeben (a eclosão) que se instala de pronto aquilo que será a memória do ser. $\mathrm{O}$ declínio e a ocultação não negam o ser, mas sim o ente. A mesmidade do ser não se corrompe com a tríade dada para a $\phi v \sigma \imath \varsigma$, mas apenas indica sua dinâmica muito particular de se revelar ocultando-se.

A definição de restauração dada por Viñas pode nos ajudar a conquistar seu sentido mais profundo. Este nos diz que a restauração "é a atividade que aspira a devolver a um estado anterior os traços perceptíveis de um bem determinado"74. A intenção aqui é dada pela noção de trazer de volta. Em momento algum estamos aqui discutindo as possíveis formas técnicas de preservação, conservação ou restauração. $\mathrm{O}$ objetivo deste escrito é discutir e conquistar determinações mais seguras para tais conceitos. Assim, o sentido buscado aqui é entender a restauração como um tomar à sua guarda (in die Acht nehmen) o ente para salvar a memória do ser na sua eclosão. A restauração quer salvar (retten) a Aufgeben; trata-se de recompor, a partir do declínio ou mesmo da ocultação, o mesmo, o idêntico que se dá na multiplicidade. Tal pro-duzir pode operar tanto no sentido da técnica moderna quanto no sentido grego da $\pi \circ 1 / \eta \sigma \iota \varpi$, ou seja, a "pro-dução da verdade na beleza"75.

Os sentidos conquistados até aqui para preservar e conservar tornam a tarefa de definir a restauração muito mais fácil. Como indicado anteriormente, este conceito também trafega nas esferas ontológica e ôntica. Assim temos: 1. Restaurar, em sentido ontológico, é o processo pelo qual o ente retorna à esfera da eclosão (Aufgeben) após transitar pelo declínio (Untergeben) elou pela ocultação (Verbergung); 2. Também indica ação exterior para marcar, dentro da história do ente, seu retorno à eclosão; 3. Em sentido ôntico, trata-se de, através de ações exteriores, devolver as características fundamentais a determinado ente para que o mesmo possa se mostrar como da sua eclosão; 4. Restaurar indica o processo de trazer de voltar ou salvar o idêntico no seio da expressão de um determinado ente que se mostra no declínio ou próximo do ocultamento.

O percurso que encetamos até aqui - iniciando com a compreensão grega do ser e do não-ser, do uno e do múltiplo, passando pela definição de mundo, ação e patrimônio - nos conduziu da ontologia grega à ontologia fundamental que serviu como guia para conquistarmos as definições dadas. De fato, um processo filosófico nunca acaba em si mesmo e toda e qualquer conquista indica apenas que novas frentes foram abertas. Tais frentes, no universo muito particular da Filosofia, jamais podem ser consideradas como definitivas, pois parece evidente que no processo histórico em que o

\footnotetext{
${ }^{73}$ SANTOS, 1985, p. 114.

74 VIÑAS, 2003, p. 24.

${ }^{75}$ HEIDEGGER, 2002, p. 36.
} 
pensamento se desenvolve ou, melhor ainda, se dá, toda conquista é sempre um ir além que, no futuro, se torna estanque e serve mesmo como impulso para novas descobertas.

\section{Referências}

APEL, Karl-Otto. Transformação da Filosofia I. São Paulo: Loyola, 2000.

BACHELARD, Gaston. Le Nouvel Esprit Scientifique. 6. ed. Paris: Quadrige, 1999.

BERENSON, Bernard. Estética e História. São Paulo: Perspectiva, 1972.

BO, J. B. Lanari. Proteção do Patrimônio na UNESCO. Brasília: UNESCO, 2003.

COCCO, Ricardo e FLEIG, Mário. A questão da técnica em Martin Heidegger. Revista Controvérsia, v. $2 \mathrm{n}^{\circ} 1$, jan-jun 2006.

DEWEY, John. A Filosofia em Reconstrução. São Paulo: Nacional, 1958.

GREGOTTI, Vittorio. Território da Arquitetura. São Paulo: Perspectiva, 1975.

HEIDEGGER, Martin. Sein und Zeit. 19. ed. Tübigen: Verlag, 2006.

. Ser e Tempo. 2. ed. Vol. I. Petrópolis: Vozes, 1988.

O Princípio do Fundamento. Lisboa: Piaget, 1999.

. Carta Sobre o "Humanismo". In:

Conferências e Escritos Filosóficos. 2. ed.

São Paulo: Abril, 1984. (Os Pensadores).

2002. . A questão da técnica. In:

Ensaios e Conferências. 2. ed. Petrópolis: Vozes,

. Logos (Heraclito, fragmento 50). In:

Ensaios e Conferências.

O Princípio do Fundamento. Lisboa: Piaget, 1999.

. Os Conceitos Fundamentais da Metafísica. Rio de Janeiro: Forense, 2003.

KANT, Immanuel. Crítica da Razão Pura. São Paulo: Abril, 1983.

LOPARIC, Zeljko. Heidegger e a pergunta pela técnica. Cadernos de História e Filosofia da Ciência, São Paulo, UNICAMP série 3, v. 6, n.2.

MERLEAU-PONTY, Maurice. Fenomenologia da Percepção. São Paulo: Martins Fontes, 1999.

PLATÃO. A República. São Paulo: Perspectiva, 2006.

Fédon, 99 d-100 a . Lisboa: EA, 1990.

O Sofista. São Paulo: DPL, 2005.

Parmênides. São Paulo: Loyola, 2003.

POPPER, Karl. Realism and the aim of science. Nova York: Routledge, 1983.

PÖGGELER, Otto. Metaphysics and Topology of Being in Heidegger. Man and Work, 8, 1975.

REALE, Giovanni. História da Filosofia Antiga. Vol. VI. São Paulo: Loyola, 1994.

SANTOS, José Trindade. Antes de Sócrates. Lisboa: Gradiva, 1985.

"Existir" e "existência" em Platão. Revista Disputatio, no 16, maio de 2004.

SERRA, Geraldo. O Espaço Natural e a Forma Urbana. São Paulo: Nobel, 1987.

WITTGENSTEIN, Ludwig. Investigações Filosóficas. 2. ed. Petrópolis: Vozes, 1996.

ZARADER, Marlene. Heidegger e as palavras de origem. Lisboa: Piaget, 1998. 